\title{
城市市政道路设计常见问题及设计方法
}

\author{
胡浩
}

南京市市政设计研究有限责任公司湖北分公司，湖北 武汉 430070

[摘要]在当前时期，国内城市的规模正逐渐扩大，大量的资源朝向城市集中，在此背景下，城市人口数量大幅增加，为了保 证城市运行更为顺畅, 市民生活需要得到满足, 必须要完成好道路设计工作, 将更为先进的设计理念予以应用。从传统设计 来看, 关注的重点交通需求基本满足, 然而和城市发展并不同步, 甚至会产生一定的限制。为了保证城市能够真正实现可持 续发展, 在对城市道路进行设计的过程中应该要对城市发展需求予以重点关注, 设计时应该要考虑市政基础设施、城市景观、 市政运营等方面的需求, 将景观、环保等理念予以有效落实。文章主要针对市政道路设计展开深入探析, 将存在的问题突显 出来, 在此基础上提出切实可行的设计方法, 确保城市发展能够更为稳健。

[关键词]市政道路设计; 问题; 设计方法

DOI：10.33142/sca.v3i3.2049 中图分类号：U412.37 文献标识码：A

\section{Common Problems and Design Methods of Urban Municipal Road Design}

\author{
HU Hao
}

Hubei Branch of Nanjing Municipal Design and Research Institute Co., Ltd., Wuhan, Hubei, 430070, China

\begin{abstract}
In the current period, the scale of domestic cities is gradually expanding, and a large number of resources are concentrated in cities. In this context, the number of urban population has increased significantly. In order to ensure the smooth operation of the city and the satisfaction of citizens' life, we must complete the road design work and apply more advanced design concepts. From the perspective of traditional design, the focus of traffic demand is basically met, but it is not synchronized with the urban development, and even has some limitations. In order to ensure that the city can truly achieve sustainable development, in the process of urban road design, we should focus on the needs of urban development. In the design, we should consider the needs of municipal infrastructure, urban landscape, municipal operation and other aspects, and effectively implement the concepts of landscape and environmental protection. This paper mainly focuses on the in-depth analysis of municipal road design, highlighting the existing problems, and on this basis, puts forward practical design methods to ensure that the urban development can be more stable.
\end{abstract}

Keywords: municipal road design; problems; design method

\section{引言}

在国内经济发展速度持续加快之际, 城市发展也明显加快, 市政道路建设的受关注程度随着提升, 因而必须要完 成好相关的设计工作。对于设计人员来说, 必须要对设计要求有清晰的认知, 对各种影响因素也要有一定的了解, 采 用先进的理念来指导整个设计工作，以期使得设计质量大幅提高。

\section{1 市政道路设计要求}

\section{1 安全方面的要求}

安全是不可忽视的问题, 对市政道路进行设计的过程中, 安全应该要予以重点关注, 也就是设计中应该要保证道 路安全不会受到任何影响。若想保证社会保持和谐发展, 一定要保证交通安全, 因而设计时应该要确保道路性质的判 断是非常精准的, 平交道口应该要设计最为合理, 立体交叉能够更为科学, 如此才能使得车辆行驶更为顺畅、安全。

\section{2 环保方面的要求}

随着社会发展, 环境保护成为了大家关注的焦点。现阶段, 国内经济呈现出良好的发展趋势, 大家的物质水平有 了明显的提升, 出行方式也也随之改变, 乘车、驾车出行成为了大家的首选。然而当机动车保有率大幅增加后, 对环 境造成的破坏变得更为严重, 尤其是空气质量明显降低。因而在展开市政道路设计时, 必须要将环保理念纳入其中, 制定出切实可行的环保制度，保证环境污染能够得到有效控制。 


\section{3 经济方面的要求}

展开市政道路建设的过程中, 除了要保证施工质量达到标准要求外, 同时对施工成本进行控制, 如此才能带来良好 的经济效益。正式设计前要完成好调研工作, 了解公共设施、现有道路的实际状况, 尤其是要获得交通的性质、流量 等方面的数据。设计过程中要将地形作为出发点, 保证路线设计、断面设计是最为合理的, 如此可以使得车辆行驶的 速度最为合适, 并可保证道路通畅。当然, 分散道路的设计可以适当降低标准, 选择远近结合设计方法, 如此可以使 得施工成本控制在合理范围内。

\section{2 市政道路特色化设计}

\section{1 城市市政道路设计必须反映出城市特征}

城市发展的速度虽然在加快, 然而不少的城市已经出现了特色退化的现象, 文化认知明显降低。当前时期, 大家 的物质生活已经有了明显的提高, 精神追求也变得更加多元, 城市应该要通过自身拥有的特色来满足这样的需求。所 以说, 在对市政道路展开设计时, 必须要对此予以重视, 将城市已经存在的自然景观、历史文化等突显出来, 尤其是 要保证城市特征可以充分彰显, 确保城市形象能够更具整体性、和谐性。设计时要关注城市自然、地形等方面的实际 特点，并对其予以充分利用，如此方可使得城市特色真正反映出来，同时可以使得成本投入切实降低。

\section{2 城市市政道路的设计必须具备功能特征}

市政道路有着自身的特殊要求, 游览、交通、生活等方面的功能必须要满足需要, 而且要兼具美观性。市政道路具 有的这些功能应该要充分展现出来, 为城市发展产生促进作用, 满足广大市民工作、生活的内在需求。 ${ }^{[2]}$

\section{3 城市市政道路设计中常见问题}

\section{1 缺乏设计经验、设计理念存在一定问题}

从市政道路设计的现状来看, 有些设计人员并未认识到路网设计的重要性, 在展开设计工作时, 将关注点放在了 路面宽度、坚固度等方面, 这就导致设计中存在明显的缺陷。从事市政道路设计的人员中, 大学应届毕业生的占比是 较大的, 这些设计人员虽然拥有一定的专业知识, 但经验是不足的, 设计过程中难以将理论、实践结合起来, 尤其是 在进行钢结构设计时, 此方面的设计经验更是严重缺乏, 这就导致设计深度达不到要求, 钢结构的安全性、稳定性未 能得到应有重视, 这样就会出现设计效果、设计理想相脱节的现象, 设计质量自然也就难以保证, 尤其是结构设计无 法达到既定的标准要求。

\section{2 交通分析不足}

若想保证市政道路设计能够达到要求, 必须要完成好交通分析工作, 简单来说就是要对车辆的组成、速度、流量 等展开全面的分析。但是从实际情况来看, 虽然展开了相关的分析工作, 但是分析的全面性较低, 导致设计人员对道 路现状并不是很了解, 这样使其主观判断出现失误, 在进行市政道路设计时无法获得准确的依据, 设计出现偏差也就 难以避免。比如在进行人行道的设计时, 要严格按照相关规定执行, 不得随意的进行主观更改。

表 1 人行道设计宽度

\begin{tabular}{c|c|c}
\hline \multirow{2}{*}{ 项目 } & \multicolumn{2}{|c}{ 人行道最小宽度 $(\mathrm{m})$} \\
\cline { 2 - 3 } & 大城市 & 中小城市 \\
\hline 各级道路 & 3 & 2 \\
\hline 商业中心路段 & 5 & 3 \\
\hline 火车站、码头路段 & 5 & 4 \\
\hline 汽车站路段 & 4 & 4 \\
\hline
\end{tabular}

\section{3 横纵断面设计存在的问题}

进行道路设计时, 横纵断面设计是不可忽视的, 其对车辆安全行驶能够产生很大影响。进行横纵断面设计的过程 中, 应该要完成好整体规划工作, 确保技术规范能够落实到位, 同时要依据实际来进行设计, 确保安全不会出现问题, 
美观也能够切实展现出来。比如双幅路设计如下:

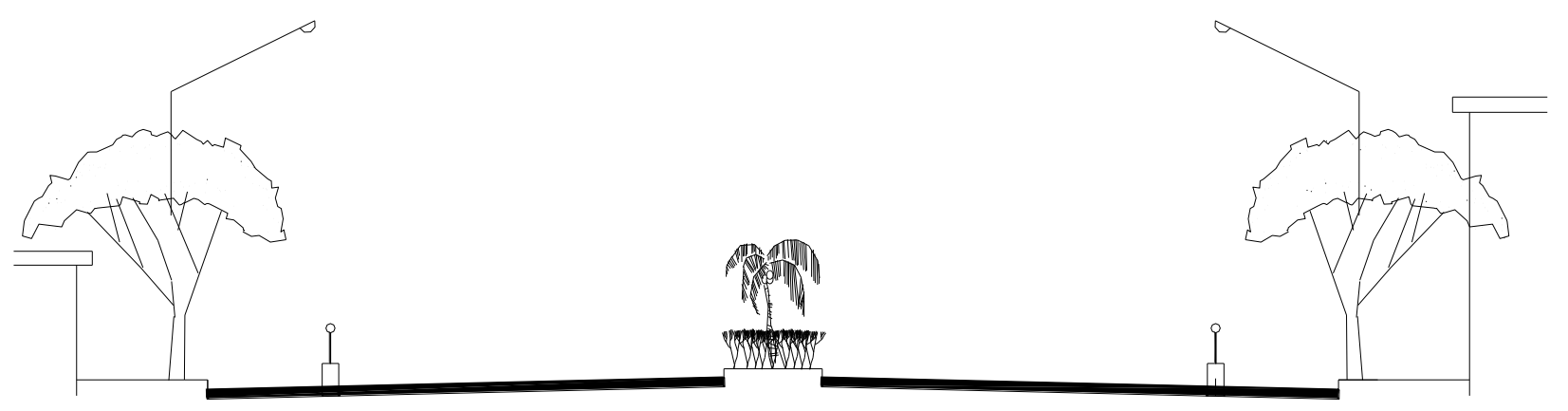

图 1 双幅路断面设计图

然而不少的设计人员并未对道路周边的建筑、管道等予以关注, 进行横断面设计的过程中未能保证道宽、隔离满 足需要, 这就使得车道划分显得过于模糊, 尤其是机动车道、非机动车道没有予以物理隔离, 这样就使得交通安全事 故的发生几率大幅增加。

\section{4 不重视绿化工作}

展开市政道路建设时, 道路绿化应该得到重视, 然而实际情况并非如此, 很多的设计人员没有认识到绿化的价值所 在, 对绿化功能未能形成正确的认知, 设计过程中没有考虑到设计美感, 这就使得设计显得过于简单。另外, 设计时 也未考虑到城市现状, 道路功能、自然环境的分析工作没有做到位, 这就使得道路设计和街道景观无法融合起来, 绿 化具有的实际价值就很难发挥出来, 整个设计质量也就变得较为低下。3ㅣ

\section{4 城市市政道路设计方法分析}

\section{1 加强对图纸设计的要求}

市政道路实用性、安全性若想得到提升的话, 必须要保证设计图纸是最为合理的。从事图纸设计的相关人员应该 要完成好路网分析工作, 将车流量、速度、网络构成等要有清晰的了解, 在此基础上完成设计工作, 如此方可保证图 纸满足建设的是需要。当然, 设计的过程中还应该完成好道路建设规划工作, 使得道路建设能够有序展开, 如此方可 使得车辆行驶的更为安全。

\section{2 城市市政道路景观道路的设计}

景观道路应该要将城市面貌清晰呈现出来，同时要能够将城市拥有的特色予以彰显。对景观道路进行规划设计的 过程中, 应该要将城市整体规划作为依据, 比方说, 道路沿线应该要保留一定的公园绿地, 此外要保证开放型空间能 够满足实际需要。在对绿化用地予以确定时, 应该要保证其和区域人口数量是相符的, 道路交叉口则要确保空间适合, 车辆经过时不会带来严重的不适感，交叉口、广场景观应该要予以整合，同时应保证交通分工是更为合理的。在完成 景观道路设计的过程中, 应该要选择合适的数种, 并要保证搭配是最为合理的, 造型应该要呈现出多样性, 使得道路 景观能够更加丰富, 如此才能保证城市环境的改善程度大幅提高。

\section{3 横纵断面设计}

进行横纵断面设计的过程中, 对道路等级、服务功能等应该要予以重点关注, 确保交通功能方面的实际需要能够 得到切实满足。设计中要对地形予以充分利用, 排水管道应该切实关注, 确保排水效果更为理想, 车辆行驶能够更加 舒适。设计道路节点时应该要确保连接是顺畅的, 行车速度也应该达到要求, 而且整个设计应呈现出美观性。纵坡设 计应该保证坡度尽量减小, 如果和建筑、河道相连接的话, 必须要确保带来的影响能够切实消除。除此以外, 对横断 面形式予以确定时, 应该要保证不会超出道理宽度范围, 相关的分析工作必须要严谨, 在此基础上将车道宽度、类型 予以确定。如果条件合适的话, 对机动、非机动车道应该予以物理隔离, 这样可以使得道路安全得到切实保证, 而且 可以使其更为美观。 


\section{4 市政道路路面的排水设计}

（1）展开车行道排水设计时, 可以采用的方式有两种, 即双坡排水、单坡排水。如果车道宽度相对较宽的话, 若想 保证径流时间切实减少, 能够在最短时间内完成排水, 最好选择双坡排水方法。对雨水口进行设置时, 间距一定要控制 到位，如此可以使得路面水收集更为理想，地表水能够通过雨水支管进入到主干管道，最终进入到水系或是河流中。

（2）展开人行道排水设计时, 若想使得排水更为顺利, 其横坡的坡度应该偏向车行道, 这样就可通过位于车行道 中的雨水口实现排出目标。挖方路段应该要在两侧增加挡土墙, 而且挡土墙上端则要设置好截水沟, 这样可以使得地 表水得到有效控制。当然, 有些地表水会经过泄水孔流入到人行道上, 继而流入位于车行道中的雨水口, 这样就可实 现排出的目的。

\section{5 道路绿化设计}

对道路进行绿化可以使得噪声污染切实降低, 而且能够使得环境更具美感, 此外可以用来对道路进行分隔, 这样就 可使得车辆行驶安全切实提高。在进行设计时, 转弯道外侧、凸形坚曲线两侧应该栽种一些高大乔木, 这样可以提醒 路线变化, 对行车安全能够起到促进作用。

\section{5 结语}

由上可知, 市政道路施工是较为复杂的, 在建设过程中, 道路状况、城市规划、周边建筑等均是不可忽视的, 因 而在展开市政道路设计时必须要将安全、环保等方面的要求予以有效落实, 保证设计方法是最为合理的, 尤其是要将 线形、横纵断面以及绿化等方面的设计做到位，如此方可使得市政道路满足大家的实际需要，并为城市发展贡献力量。

\section{[参考文献]}

[1]黄永彦.试析城市市政道路设计常见问题及设计方法 [J].江西建材,2017 (13) : 162-167.

[2]张荣华.城市市政道路设计常见问题及设计方法 [J].住宅与房地产, 2016 (30): 69.

[3]陈云.浅析城市市政道路设计常见问题及设计方法 [J].建材与装饰, 2016 (19) : 106-107.

[4] 黄深栋. 城市市政道路设计常见问题及设计方法 [J]. 建材与装饰, 2016 (08) : 91-92.

[5]孟宝全. 试析城市市政道路设计常见问题及设计方法 [J].建材与装饰,2015(49): 276-277.

作者简介: 胡浩 (1993.1-), 男, 武汉科技大学, 工程管理, 南京市市政设计研究有限责任公司湖北分公司, 助理工 程师。 